\title{
Risk of Stroke according to the Duration of Diabetes Mellitus with Hypertension
}

\author{
Hee Sung Kim
}

Department of Biomedical Laboratory Science, Catholic Kwandong University, Gangneung, Korea

\section{고혈압을 동반한 당뇨병에서 유병기간에 따른 뇌졸중 위험도 김희성}

가톨릭관동대학교 임상병리학과

\section{ARTICLE INFO}

Received June 22, 2020

Revised $1^{\text {st }}$ July 29,2020

Revised $2^{\text {nd }}$ August 13, 2020

Revised $3^{\text {rd }}$ August 24, 2020

Accepted August 25, 2020

\section{Key words}

Hypertension

Diabetes mellitus complication

Stroke

\begin{abstract}
Stroke is a major cause of death and disorder, and diabetes mellitus (DM) is a significant risk factor of stroke. This study examined the importance of target blood pressure $(<140 /<90 \mathrm{mmHg})$ management in patients with DM. Based on the data of the 6th National Health and Nutrition Examination Survey, a total of 16,389 patients aged 18 to under 80 were assessed through regression analysis to estimate the risk of stroke through blood pressure control. The prevalence of stroke according to the presence or absence of DM was higher in the diabetic group, and a longer duration of DM indicated a higher risk of hypertension and stroke. The hazard ratio of stroke was lower in the maintenance group (0.57) of target blood pressure $(<140 /<90 \mathrm{mmHg})$ compared to the high blood pressure group $(>140 />90 \mathrm{mmHg})$. Despite the accompanying treatment for DM and hypertension, the frequency of hypertension increased, and the prevalence of stroke increased after five years of DM. Hence, effective blood pressure management at this time is important. The risk of stroke should be reduced by continuously managing blood pressure in DM.
\end{abstract}

Copyright (C) 2020 The Korean Society for Clinical Laboratory Science. All rights reserved.

\section{서 론}

전 세계적으로 허혈성 뇌졸중은 사망발생 요인 및 여러 장기 의 장애를 일으키는 주요 원인 중 하나이고, 제 2 형 당뇨병 (T2DM)은 허혈성 뇌졸중의 주요 위험 인자이다[1, 2]. T2DM 환자에서 허혈성 뇌졸중의 위험성은 2 6배 높고, 재발 위험성, 중증의 뇌졸중 및 사망률 증가와 관련되어 있다[3-5]. 허혈성 뇌 졸중의 급성기에는 잦은 고혈당증이 관찰되며 그 결과 경색이 심해지고 예후가 악화된다[6]. 특히 뇌졸중 발생 초기 24시간 동 안 혈당이 지속적으로 $200 \mathrm{mg} / \mathrm{dL}$ 이상일 경우, 독립적으로 허

Corresponding author: Hee Sung Kim

Department of Biomedical Laboratory Science, Catholic Kwandong University, 24 Beomil-ro 579beon-gil, Gangneung 25601, Korea

E-mail: praylake7@gmail.com

ORCID: https://orcid.org/0000-0002-7317-4007
혈성 부위의 범위확대와 신경학적인 이상결과를 예측할 수 있 다. 이는 고혈당 관리가 허혈성 뇌졸중 환자에 있어 필수적으로 관리해야 할 부분임을 알려준다[7]. 뇌졸중에는 식습관 같은 수 정 가능한 위험 요인과 연령, 인종처럼 수정 불가능한 위험 요인 을 포함하는 수많은 위험 요인이 있다. 전염병, 패혈증, 스트레 스와 같은 단기적인 유발 요인, 고혈압, 고지혈증과 같은 중기적 인 위험 요인, 성별에 따른 장기적인 위험 요인이 있다[8]. 2018 년 국제뇌졸중협회[9]에서는 뇌졸중 발생위험요인을 첫 번째, 흡연, 음주, 체질량지수 $[10,11]$, 고혈압 등 위험요인 진단 후 치 료약물복용 이행여부[12]를 포함하는 생활습관, 두 번째, 간기 능 수치(AST, ALT), 당화혈색소[13], 콜레스테롤(총콜레스테 롤, LDL-콜레스테롤), 중성지방[10, 12], 수축기 및 이완기 혈 압과 과거력으로 고혈압, 당뇨, 고지혈증[12, 13], 심방세동 [14], 일과성 허혈발작[13]을 포함하는 임상적 위험요인으로 구 
분하였다. 본 논문에서는 제6기 국민건강영양조사를 토대로 뇌 졸중의 원인 요인 가운데 고혈압을 중점으로, 한국인 당뇨병 환 자들의 유병기간동안 고혈압 조절에 따른 뇌졸중 위험도의 변화 양상을 밝히는 것을 목적으로 한다.

\section{재료 및 방법}

\section{1. 연구대상}

본 연구는 제6기 국민건강영양조사(2013 2015년)의 원시 데이터 자료를 이용하였다. 한국인 전체를 모집단으로 하는 순 환표본조사이자 전국 규모의 횡단적 연구이다. 본 연구에서는 당뇨환자 1,733 명과 정상인 14,656 명 총 16,389 명을 대상으 로 하였으며, 18 세 이상 80세 미만으로 나이를 제한하였고, 임 신부는 연구에서 제외하였다. 본 연구는 가톨릭관동대학교 기 관생명윤리심의회(IRB, Institutional Review Board)의 승인 하에 시행하였다(IRB Approval Number: CKU-20-01-0608).

\section{2. 당뇨병과 그 외 질병 및 위험인자의 기준}

당뇨병 질환 대상자는 대한당뇨병학회에서 제시한 당뇨병 진 료지침[15]를 기준으로 공복혈당 $126 \mathrm{mg} / \mathrm{dL}$ 이상이거나, 의 사진단을 받았거나 혈당강하제를 복용하거나 인슐린주사를 투 여 받고 있는 사람인 경우로 분류하였다[16]. 고혈압은 수축기 혈압이 $140 \mathrm{mmHg}$ 이상, 이완기 혈압이 $90 \mathrm{mmHg}$ 이상, 항고 혈압제 사용 또는 의사의 고혈압 진단으로 정의하였다[17]. 고 지혈증은 총 콜레스테롤 $\geq 240 \mathrm{mg} / \mathrm{dL}, \mathrm{HDL}$-콜레스테롤(전 환식) 남성 $<50 \mathrm{mg} / \mathrm{dL}$ (여성 $<40 \mathrm{mg} / \mathrm{dL}$ ), LDL-콜레스테롤 $\geq 160 \mathrm{mg} / \mathrm{dL}$, 중성지방 $\geq 200 \mathrm{mg} / \mathrm{dL}$, 지질 저하약물사용또 는 의사의 진단으로 정의된다[18]. HDL-콜레스테롤은 고콜레 스테롤혈증은 공복시 총콜레스테롤 $\geq 240 \mathrm{mg} / \mathrm{dL}$ 또는 콜레스 테롤 약을 복용하는 자를 의미하고, 고중성지방혈증은 12 시간 이상 공복 시 중성지방 $200 \mathrm{mg} / \mathrm{dL}$ 이상으로 정의하고, 저 $\mathrm{HDL}$-콜레스테롤혈증은 8시간 이상 공복자 중 $\mathrm{HDL}$-콜레스테 롤이 $40 \mathrm{mg} / \mathrm{dL}$ 미만인 자를 가리키며, 이를 이상지질혈증이라 한다.

\section{3. 인구통계학과 인체측정법}

국민건강영양조사에서 제시한 방법에 따라, 인체측정 데이 터 및 혈액 생체 표지자는 숙련된 의료진이 건강 검진을 통해 평 가했다. 흡연상태는 전혀 흡연을 하지 않은 자, 과거 흡연자, 현 재 흡연자로 구분하였다. 체질량 지수는 체중 $(\mathrm{kg})$ 을 신장 $(\mathrm{m})$ 제 곱으로 나눈 값으로 계산되었다. 체질량 지수는 정상 18.5
$25.0 \mathrm{~kg} / \mathrm{m}^{2}$, 저체중 $<18.5 \mathrm{~kg} / \mathrm{m}^{2}$, 과체중 $\geq 25.0 \mathrm{~kg} / \mathrm{m}^{2}$, 비 만 $30.0 \mathrm{~kg} / \mathrm{m}^{2}$ 이상으로 판단하며 이는 아시아 인구에 대한 세 계보건기구의 기준에 따라 정의되었다[19].

\section{4. 데이터의 통계분석}

본 연구에 사용된 모든 통계처리는 통계 프로그램(SPSS version 23.0, SPSS Inc., Chicago, IL, USA)을 사용하였다. 연속 변수는 평균과 표준 편차를 사용하여 기술하였으며, $\mathrm{t}$-시 험, 비모수 만-휘트니 U 검증 및 일원 분산 분석을 수행하였다. 범주형 변수 간의 연관성을 평가하기 위해 카이제곱 테스트를 사용하였다. 당뇨병 발병 유무에 따른 변수들의 교차비(odds ratio, OR)와 95\% 신뢰도(confidence interval, CI)를 구하기 위하여 다항 로지스틱 회귀분석을 이용하였다. 통계적인 유의 성 검증은 유의 수준 $P<0.05$ 를 기준으로 하였다.

\section{결 과}

제6기 국민건강영양조사의 자료를 토대로 당뇨병이 없는 일 반인을 대조군으로, 당뇨병 환자에서 뇌졸중을 않고 있는 군과 뇌졸중을 않고 있지 않은 군으로 구분하여 남녀 구분하여 임상 적 특성을 분석하였다(Table 1). 당뇨병 유병기간은 뇌졸중을 가진 군(남, $12.8 \pm 9.4 ;$ 여, 10.5 \pm 7.6 )이 뇌졸중이 없는 군(남,

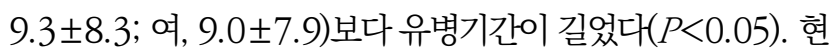
재 흡연율은 여성에 비해 남성이 높고, 수축기 혈압은 대조군에 비해 당뇨병 환자가 높았다 $(P<0.05)$.

당뇨병 유병기간에 따른 고혈압의 유병률은 당뇨병 유병기간 이 길어질수록 고혈압 유병률은 상승하였다(Figure $1 \mathrm{~A}, 1$ 년 미 만: $60.0 \%, 16$ 년 이상: $70.8 \%, P<0.05)$. 당뇨병 유무에 따른 뇌졸중의 유병률은 당뇨병 환자군(7.7\%)과 당뇨병이 없는 군 (1.8\%)으로 구분하였을 때 당뇨병 환자 군에서 높았다(Figure $1 \mathrm{~B}, P<0.05)$. 당뇨병 환자에서 고혈압 유병기간에 따른 고혈압 및 당뇨병 치료양상은 질병초기(1년 미만)를 제외하고 $71 \%$ 이 상, 최대 $99.0 \%$ 로 적극적인 치료를 받고 있음을 확인하였다 (Figure 1C, $P<0.05$ ). 당뇨병 유병기간에 따른 적정 혈압 유지 군 $<140 /<90 \mathrm{mmHg}$ )과 고혈압군에서 뇌졸중의 유병률은 당뇨병 유병기간 16 년이상에서 고혈압군(25.5\%)이 적정 혈압 유지군(10.2\%)에 비해 높았다(Figure $1 \mathrm{D}, P<0.05$ ). 또한, 당 뇨병 유병기간동안 뇌졸중에 대한 위험비(hazard ratio, $\mathrm{HR}$ ) 는 고혈압군 $1.74(95 \% \mathrm{CI}, 1.28$ 2.37) 대 적정 혈압 유지군 1.17 (95\% CI, 0.98 1.41)로 적정 혈압 유지군에서 뇌졸중 위 험성은 낮았다. 
190 Hee Sung Kim. Risk of Stroke according to Diabetes Mellitus with Hypertension

Table 1. Analysis of clinical characteristics of stroke by gender in diabetic patients

\begin{tabular}{|c|c|c|c|c|c|c|c|}
\hline & \multicolumn{4}{|c|}{$\mathrm{DM}$} & \multirow{2}{*}{\multicolumn{2}{|c|}{ Normal }} & \multirow{3}{*}{$P$-value } \\
\hline & \multicolumn{2}{|c|}{ With stroke } & \multicolumn{2}{|c|}{ Without stroke } & & & \\
\hline & Female & Male & Female & Male & Female & Male & \\
\hline Population (N) & $62(46.6 \%)$ & $71(53.4 \%)$ & $786(49.1 \%)$ & $814(50.9 \%)$ & $8,416(57.4 \%)$ & $6,240(42.6 \%)$ & \\
\hline Mean age (years) & $68.5 \pm 7.0$ & $65.2 \pm 8.1$ & $62.7 \pm 11.7$ & $60.8 \pm 11.3$ & $16.0 \pm 15.7$ & $47.6 \pm 16.5$ & $<0.05$ \\
\hline Mean diabetes duration & $10.5 \pm 7.6$ & $12.8 \pm 9.4$ & $9.0 \pm 7.9$ & $9.3 \pm 8.3$ & NA & NA & $<0.001$ \\
\hline \multicolumn{8}{|l|}{ Smoking status (\%) } \\
\hline Never smoker & $88.5 \%$ & $15.7 \%$ & $90.2 \%$ & $17.5 \%$ & $89.6 \%$ & $22.9 \%$ & $<0.001$ \\
\hline Past smoker & $3.3 \%$ & $48.6 \%$ & $4.4 \%$ & $46.4 \%$ & $5.3 \%$ & $38.1 \%$ & $<0.001$ \\
\hline Current smoker & $8.2 \%$ & $35.7 \%$ & $5.3 \%$ & $36.2 \%$ & $5.1 \%$ & $38.9 \%$ & $<0.001$ \\
\hline Mean BMI & $26.2 \pm 4.1$ & $24.3 \pm 3.3$ & $25.5 \pm 3.7$ & $24.9 \pm 3.4$ & $23.2 \pm 3.4$ & $24.2 \pm 3.3$ & $<0.001$ \\
\hline Underweight $\left(<18.5 \mathrm{~kg} / \mathrm{m}^{2}\right)$ & $0.0 \%$ & $0.0 \%$ & $1.1 \%$ & $1.5 \%$ & $5.7 \%$ & $2.9 \%$ & $<0.001$ \\
\hline Normal $\left(18.5 \sim 24.9 \mathrm{~kg} / \mathrm{m}^{2}\right)$ & $46.8 \%$ & $57.7 \%$ & $50.3 \%$ & $52.3 \%$ & $66.7 \%$ & $59.4 \%$ & $<0.001$ \\
\hline Overweight $\left(25.0 \sim 29.9 \mathrm{~kg} / \mathrm{m}^{2}\right)$ & $35.5 \%$ & $36.6 \%$ & $37.2 \%$ & $39.3 \%$ & $23.7 \%$ & $33.0 \%$ & $<0.001$ \\
\hline Obese $\left(>30.0 \mathrm{~kg} / \mathrm{m}^{2}\right)$ & $17.7 \%$ & $5.6 \%$ & $11.4 \%$ & $6.9 \%$ & $3.9 \%$ & $4.7 \%$ & $<0.001$ \\
\hline Drinking (\%) & $41.9 \%$ & $53.5 \%$ & $48.0 \%$ & $77.5 \%$ & $66.6 \%$ & $84.7 \%$ & $<0.001$ \\
\hline \multicolumn{8}{|l|}{ Blood pressure } \\
\hline $\mathrm{SBP}(\mathrm{mmHg})$ & $130.9 \pm 19.0$ & $129.7 \pm 21.6$ & $126.3 \pm 17.7$ & $124.6 \pm 15.9$ & $114.8 \pm 17.0$ & $119.9 \pm 15.0$ & $<0.001$ \\
\hline $\mathrm{DBP}(\mathrm{mmHg})$ & $72.6 \pm 12.2$ & $74.1 \pm 12.4$ & $73.0 \pm 9.7$ & $75.8 \pm 11.1$ & $73.1 \pm 9.7$ & $77.7 \pm 10.4$ & $<0.001$ \\
\hline Glucose (mg/dL) & $142.3 \pm 39.4$ & $129.1 \pm 32.0$ & $142.1 \pm 45.4$ & $143.2 \pm 41.4$ & $93.4 \pm 10.2$ & $96.5 \pm 11.9$ & $<0.001$ \\
\hline Mean $\mathrm{HbA1c}(\%)$ & $7.1 \pm 1.1$ & $7.2 \pm 1.5$ & $7.4 \pm 1.3$ & $7.3 \pm 1.4$ & $5.6 \pm 0.4$ & $5.6 \pm 0.4$ & $<0.001$ \\
\hline Dyslipidemia (\%) & $74.2 \%$ & $69.0 \%$ & $65.5 \%$ & $63.8 \%$ & $27.8 \%$ & $37.3 \%$ & $<0.001$ \\
\hline Mean Triglyceride (mg/dL) & $152.6 \pm 74.1$ & $155.5 \pm 99.6$ & $160.6 \pm 102.6$ & $201.2 \pm 181.4$ & $110.5 \pm 73.1$ & $155.8 \pm 125.0$ & $<0.001$ \\
\hline Mean total cholesterol $(\mathrm{mg} / \mathrm{dL})$ & $183.2 \pm 33.5$ & $160.0 \pm 34.8$ & $186.9 \pm 42.1$ & $180.9 \pm 40.2$ & $190.0 \pm 34.6$ & $187.7 \pm 34.6$ & $<0.001$ \\
\hline Mean LDL cholesterol (mg/dL) & $47.6 \pm 10.5$ & $41.8 \pm 13.0$ & $47.4 \pm 10.7$ & $44.3 \pm 10.9$ & $54.5 \pm 12.1$ & $47.9 \pm 11.0$ & $<0.001$ \\
\hline Mean HDL cholesterol (mg/dL) & $105.8 \pm 33.1$ & $85.9 \pm 27.3$ & $111.3 \pm 39.1$ & $104.7 \pm 32.3$ & $115.8 \pm 31.6$ & $114.3 \pm 31.9$ & $<0.001$ \\
\hline Mean creatinine $(\mathrm{mg} / \mathrm{dL})$ & $0.8 \pm 0.3$ & $1.4 \pm 2.1$ & $0.7 \pm 0.2$ & $1.0 \pm 0.5$ & $0.7 \pm 0.2$ & $1.0 \pm 0.3$ & $<0.001$ \\
\hline Mean hemoglobin $(\mathrm{g} / \mathrm{dL})$ & $13.0 \pm 1.4$ & $14.6 \pm 1.5$ & $13.2 \pm 1.2$ & $14.9 \pm 1.5$ & $13.1 \pm 1.1$ & $15.3 \pm 1.2$ & $<0.001$ \\
\hline \multicolumn{8}{|l|}{ Treatment } \\
\hline Insulin (\%) & $8.1 \%$ & $7.0 \%$ & $7.3 \%$ & $7.2 \%$ & NA & NA & $<0.001$ \\
\hline Oral hypoglycemic agent (\%) & $83.9 \%$ & $78.9 \%$ & $68.7 \%$ & $62.5 \%$ & NA & NA & $<0.001$ \\
\hline Diet and exercise (\%) & $1.6 \%$ & $0.0 \%$ & $0.6 \%$ & $0.9 \%$ & NA & NA & $<0.001$ \\
\hline
\end{tabular}

Abbreviations: DM, diabetes mellitus; SBP, systolic blood pressure; DBP, diastolic blood pressure; NA, not available.

\section{고 찰}

당뇨병 환자에서 고혈압, 뇌졸중의 합병증은 정상인 대조군 과 비교하여 높았다. Alloubani A 등의 연구에서 당뇨병이 있 는 사람들은 당뇨병이 없는 일반인에 비해 $1.5 \sim 3$ 배의 뇌졸중 과사망률이 높았다[20]. 독립적으로 당뇨병은 노인에게서 재발 성 뇌졸중의 $60 \%$ 의 위험성 $(\mathrm{HR}, 1.59 ; 95 \% \mathrm{CI}, 1.07$ 2.37)이 있다[21]. Goldstein 등[14]과 Burchfiel 등[22]의 연구에서 당뇨병과 허혈성 뇌졸중 사이의 위험성이 2 6배 증가한 것으 로 나타났다. Kissela 등[23]은 모든 허혈성 뇌졸중의 $40 \%$ 는 당 뇨병 단독 또는 고혈압을 동반한 당뇨병이 원인이었다. 이와같 은 현상은 동맥의 비정상적인 지방 침착, 고혈압, 고혈당증 등과 같은 두 개 내/외의 인자가 복합적으로 발생되는 혈관의 죽상동 맥경화성 변화는 높은 포도당 수치나 다른 위험요인 때문이 아 니고, 당뇨병을 유발하는 세포와 고인슐린혈증에 의한 인슐린
저항성 때문에 발생한다[20]. 당뇨병은 혈소판 응집 증가, 응고 및 유리 라디칼 형성 증가, 칼슘 조절의 변화가 확실하게 나타나 기 때문에, 어린 나이에도 죽상동맥경화증을 일으킬 수 있다 [20]. 당뇨병 환자는 다른 심혈관 위험 인자와 무관하게 혈전색 전증의 위험성이 증가한다[22]. 시간이 지남에 따라 죽상동맥경 화증의 진행은 가속화되고 비만, 콜레스테롤 상승, 당뇨병과 관 련된 고혈압 및 다른 위험 요인이 유병률 증가로 이어질 수 있다 [14].

본 연구에서는 당뇨병 환자에서 혈압관리를 중점으로 적정혈 압(<140/<90 mmHg)으로 관리한 군이 고혈압군보다 뇌졸 중의 위험률(HR)이 0.57 이 감소함을 확인하였다. 당뇨병 유병 기간이 길어짐에 따라 당뇨병과 고혈압에 대한 치료와 약제를 사용하는 빈도는 높았음에도 불구하고, 지속적으로 혈압이 상 승하고 있음을 확인할 수 있었다. 이를 통해, 혈압관리에 더욱 효 과적인 방법을 모색하고, 더욱 적극적인 관리와 치료가 필요할 

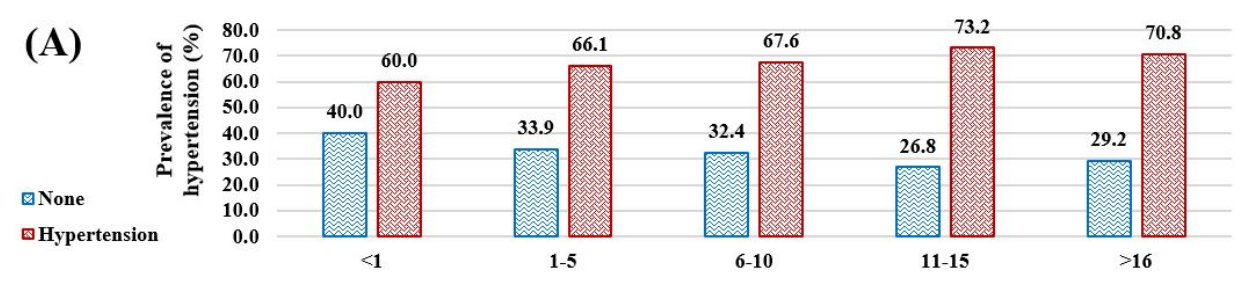

(B)

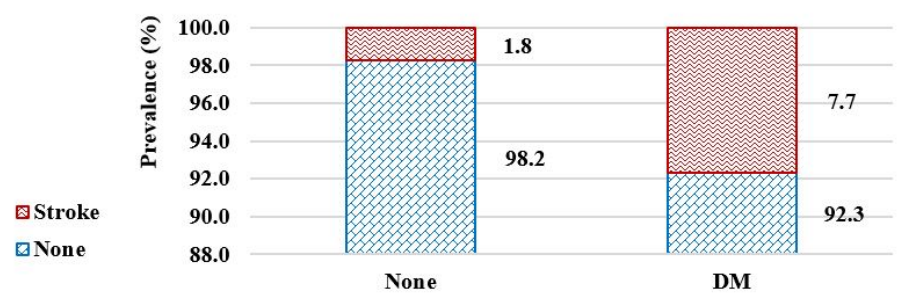

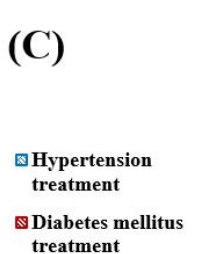
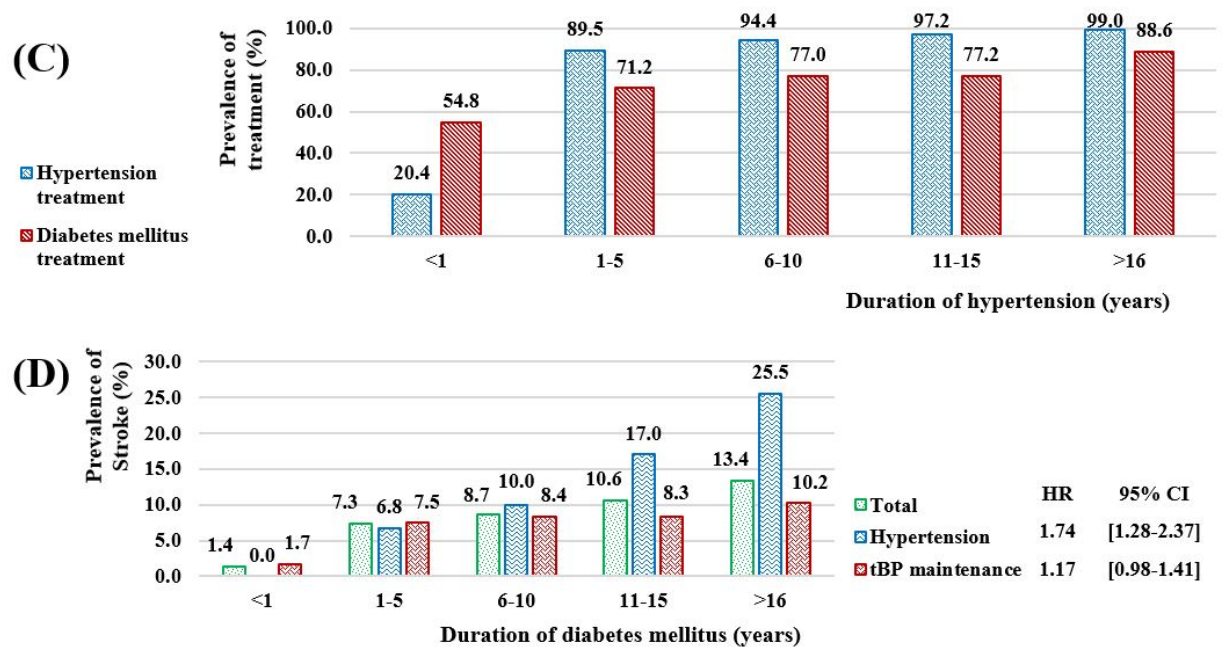

Figure 1. Analysis of the risk of stroke according to DM prevalence and blood pressure control. (A) Prevalence of hypertension according to the duration of DM (cross analysis, $\mathrm{N}=1,316, P<$ 0.001). (B) Prevalence of stroke with and without DM (cross analysis, $\mathrm{N}=14,932, P<0.001)$. (C) The rate of hypertension and DM treatment according to the duration of hypertension in DM (cross analysis, $\mathrm{N}=4,609, P<0.001$ ). (D) The risk of stroke in the group with target blood pressure (tBP) and the group with hypertension according to the prevalence of DM. HR is hazard ratio (logistic regression, $\mathrm{N}=1,306, P<$ 0.001).
것으로 사료된다. 특히, 당뇨병 유병기간이 6 10년을 기점으 로 뇌졸중 유병율이 적정혈압 관리군(8.4\%)보다 고혈압군 (10.0\%)이 높아지는 기점이 되고 있으며, 16 년 이상에서 고혈 압군의 뇌졸중 유병률이 적정혈압 군에 비해 2.05배 증가하는 소견은 당뇨병 환자의 유병기간에서 5 년 이후의 혈압을 더욱 적 극적으로 관리하는 것이 뇌졸중의 위험성을 낮추는 지표라 할 수 있다.

미국뇌졸중협회의 지침에 따르면, 혈압이 $140 / 90 \mathrm{mmHg}$ 이상인 환자의 경우 $140 / 90 \mathrm{mmHg}$ 밑으로 유지하거나, 고혈 압 환자의 경우 혈압을 낮추는 요법을 시작하는 것을 권고하고 있다. 제한하는 혈압의 기준은 개인적으로 다르겠지만, 합리적 인 목표는 $140 / 90 \mathrm{mmHg}$ 미만이다[24]. 영국전향적당뇨병연 구(UKPDS, United Kingdom Prospective Diabetes Study) 에서는 세 번의 실험을 통해, 뇌졸중의 크기를 줄이는데 있어 엄 격한 혈압 조절이 효과적이었으며, 주로 당뇨병 환자에게만 영 향을 미쳤음을 확인하였다[25]. Alloubani 등[20]은 순환계에
서 $20 \mathrm{mmHg}$ 수축기 및 $10 \mathrm{mmHg}$ 이완기 혈압상승으로 뇌졸 중과 허혈성 질환으로 인한 사망률이 2 배 정도 증가했고, 수축 기 혈압이 약 $10 \mathrm{mmHg}$, 이완기 혈압이 $5 \mathrm{mmHg}$ 감소하면 뇌 졸중으로 인한 사망 위험이 $40 \%$ 감소하고 허혈성 심장 질환과 다른 혈관 관련 사망이 $30 \%$ 감소할 수 있다고 하였다[26, 27]. James 등[17]은 표준 치료인 수축기 혈압 $140 \mathrm{mmHg}$ 미만보 다, $120 \mathrm{mmHg}$ 미만의 집중 치료가 복합 심혈관 위험성을 감소 시켰다(HR, 0.75; 95\% CI, 0.64 0.89; $P<0.001)$. Rundek 과 Sacco [28]의 연구에서 뇌졸중을 피하기 위해 당뇨병 환자의 혈압을 $140 / 90 \mathrm{mmHg}$ 미만보다는 $130 / 80 \mathrm{mmHg}$ 미만으로 조절해야 하고, 조절이 불가능하다면 약물 복용을 고려해야 하 는데, 모든 뇌졸중 환자에게 혈압 약을 추천하고, 약 $10 / 5$ $\mathrm{mmHg}$ 의 혈압이 감소한 이후에 이점이 나타난다고 하였다. 허 혈성 뇌졸중 병력이 있는 환자는 간호 시설 내에서 고지혈증 제 제인 스타틴 치료를 받고 있기 때문에 조절에 유리할 수 있다 [29]. 
본 연구는 몇 가지 제한점이 있는데, 횡단면 연구의 특성으로 당뇨병 환자의 단면적인 상황만 알 수 있고, 뇌졸중의 인과 관계 를 추정하는 것은 불가능하다. 제 1 형, 제 2 형 당뇨병을 구별하지 않았고, 제2형 당뇨병과 고혈압 환자에서 치료에 관한 세부사항 은 언급하지 않았다. 시간 경과에 따른 연속적인 검사를 진행하 지 않았으므로, 질병의 진행에 대한 정보를 제공할수 없다. 질병 의 진단 및 상황을 설문조사를 통해 과거 진단 여부를 확인하는 것을 통해 이루어졌으며, 일부 설문 항목을 대답하지 않았거나 신체 계측을 받지 않아 표본수가 적은 제한점을 가진다.

결론적으로, 당뇨병 유병기간이 길어짐에 따라 적극적인 당 뇨병 치료를 임하고 있음에도 불구하고 뇌졸중의 위험요소 중 고혈압에 대한 위험성의 중요성을 대한민국 전체를 대상으로 하 는 국민건강영양조사의 표본을 토대로 적정 혈압으로 조절하는 군에서 HR 0.57이 낮았고, 특별히 당뇨병 유병기간 5년 이후의 혈압관리가 더욱 중요함을 확인하였다. 따라서, 당뇨병 환자에 서 뇌졸중 예방을 위해 혈압을 적극적으로 효율적인 방법으로 조절하는 것이 중요하다 하겠다.

\section{요 약}

뇌졸중은 사망발생 및 장애를 일으키는 주요 원인 질환이며, 당뇨병은 뇌졸중의 주요 위험인자이다. 당뇨병 환자가운데 뇌 졸중을 동반한 환자에서 적정 혈압 관리의 중요성을 알아보고자 한다. 제6기 국민건강영양조사 자료를 바탕으로 18 세 이상 80 세 미만자 총 16,389 명을 대상으로 회귀분석을 통하여 당뇨병 유병기간에 따른 혈압조절을 통한 뇌졸중의 위험도를 산정하였 다. 당뇨병 유무에 따른 뇌졸중의 유병률은 당뇨병 환자 군에서 높았고, 당뇨병의 유병기간이 길어질수록 고혈압과 뇌졸중의 위험도는 상승하였으며, 당뇨병과 고혈압에 대한 치료 비율은 높았다. 고혈압군에 비해적정 혈압 유지군 $<140 /<90 \mathrm{mmHg}$ ) 에서 뇌졸중 위험비(HR)는 0.57 낮았다. 당뇨병과 고혈압에 대 한 치료가 동반됨에도 불구하고 고혈압의 빈도는 상승하였고, 당뇨병 유병기간 5년 이후 뇌졸중의 유병률이 상승함에 따라 이 시기의 효과적인 혈압관리가 더욱 중요하다. 당뇨병 환자에서 지속적으로 적정 혈압으로 관리함으로써 뇌졸중 위험도를 낮추 는 것이 중요하다.

\section{Acknowledgements: None \\ Conflict of interest: None}

Author's information (Position): Kim HS, Professor.

\section{REFERENCES}

1. Wang H, Naghavi M, Allen C, Barber RM, Bhutta ZA, Carter A, et al. Global, regional, and national life expectancy, all-cause mortality, and cause-specific mortality for 249 causes of death, 19802015: a systematic analysis for the Global Burden of Disease Study 2015. Lancet. 2016;388:1459-1544. https://doi.org/10. 1016/S0140-6736(16)31012-1

2. Emerging Risk Factors C, Sarwar N, Gao P, Seshasai SR, Gobin R, Kaptoge S, et al. Diabetes mellitus, fasting blood glucose concentration, and risk of vascular disease: a collaborative meta-analysis of 102 prospective studies. Lancet. 2010;375:2215-2222. https://doi.org/10.1016/S0140-6736(10)60484-9

3. Sander D, Kearney MT. Reducing the risk of stroke in type 2 diabetes: pathophysiological and therapeutic perspectives. J Neurol. 2009;256:1603-1619. https://doi.org/10.1007/s00415-009-5143-1

4. Tziomalos K, Spanou M, Bouziana SD, Papadopoulou M, Giampatzis V, Kostaki S, et al. Type 2 diabetes is associated with a worse functional outcome of ischemic stroke. World J Diabetes. 2014;5:939-944. https://doi.org/10.4239/wjd.v5.i6.939

5. Reeves MI, Vaidya RS, Fonarow GC, Liang L, Smith EE, Matulonis $\mathrm{R}$, et al. Quality of care and outcomes in patients with diabetes hospitalized with ischemic stroke: findings from Get With the Guidelines-Stroke. Stroke. 2010;41:E409-417. https://doi.org/10. 1161/STROKEAHA. 109.572693

6. Kruyt ND, Biessels GJ, Devries JH, Roos YB. Hyperglycemia in acute ischemic stroke: pathophysiology and clinical management. Nat Rev Neurol. 2010;6:145-155. https://doi.org/10.1038/ nrneurol.2009.231

7. Baird TA, Parsons MW, Phan T, Butcher KS, Desmond PM, Tress $\mathrm{BM}$, et al. Persistent poststroke hyperglycemia is independently associated with infarct expansion and worse clinical outcome. Stroke. 2003;34:2208-2214. https://doi.org/10.1161/ 01.STR.0000085087.41330.FF

8. Boehme AK, Esenwa C, Elkind MS. Stroke risk factors, genetics, and prevention. Circ Res. 2017;120:472-495. https://doi.org/ 10.1161/CIRCRESAHA. 116.308398

9. Powers WJ, Rabinstein AA, Ackerson T, Adeoye OM, Bambakidis NC, Becker K, et al. 2018 guidelines for the early management of patients with acute ischemic stroke: a guideline for healthcare professionals from the American Heart Association/American Stroke Association. Stroke. 2018;49:e46-e99. https://doi.org/10. 1161/STR.0000000000000158

10. Park TH, Ko Y, Lee SJ, Lee KB, Lee J, Han M-K, et al. Identifying target risk factors using population attributable risks of ischemic stroke by age and sex. J Stroke. 2015;17:302. https://doi.org/ 10.5853/jos.2015.17.3.302

11. KimK. Relation of stroke risk factors to severity and disability after ischemic stroke. Korean J Stroke. 2012;14:136. https://doi.org $/ 10.5853 / \mathrm{kjs} .2012 .14 .3 .136$

12. ParkJ. Stroke update 2009: Recent advances on stroke risk factors \& primary prevention. Korean J Stroke. 2009;11:62-66.

13. Baek IK, Kim YS. The case-control study on the risk factors of stroke. J Haehwa Med. 2013;22:201-216.

14. Goldstein LB, Adams R, Alberts MJ, Appel LJ, Brass LM, Bushnell $\mathrm{CD}$, et al. Primary prevention of ischemic stroke: A guideline 
from the American heart association/American stroke association stroke council: Cosponsored by the atherosclerotic peripheral vascular disease interdisciplinary working group; cardiovascular nursing council; clinical cardiology council; nutrition, physical activity, and metabolism council; and the quality of care and outcomes research interdisciplinary working group: The American academy of neurology affirms the value of this guideline. Stroke. 2006;37:1583-1633. https://doi.org/10.1161/01. STR.0000223048.70103.F1

15. Ha KH, Kim DJ. Current status of managing diabetes mellitus in Korea. Korean J Intern Med. 2016;31:845. https://doi.org/10. 3904/kjim.2016.253

16. American Diabetes Association. Standards of medical care in diabetes-2015 abridged for primary care providers. Clin Diabetes. 2015;33:97-111. https://doi.org/10.2337/diaclin.33.2.97

17. James PA, Oparil S, Carter BL, Cushman WC, DennisonHimmelfarb C, Handler J, et al. 2014 evidence-based guideline for the management of high blood pressure in adults: report from the panel members appointed to the Eighth Joint National Committee (JNC 8). JAMA. 2014;311:507-520. https://doi.org/ 10.1001/jama.2013.284427

18. Expert Panel on Detection E, Treatment of High Blood Cholesterol in A. Executive Summary of The Third Report of The National Cholesterol Education Program (NCEP) Expert Panel on Detection, Evaluation, And Treatment of High Blood Cholesterol In Adults (Adult Treatment Panel III). JAMA. 2001;285:2486-2497. https://doi.org/10.1001/jama.285.19.2486

19. Nam GE, Park HS. Perspective on diagnostic criteria for obesity and abdominal obesity in Korean adults. J Obes Metab Syndr. 2018;27:134. https://doi.org/10.7570/jomes.2018.27.3.134

20. Alloubani A, Saleh A, Abdelhafiz I. Hypertension and diabetes mellitus as a predictive risk factors for stroke. Diabetes Metab Syndr. 2018;12:577-584. https://doi.org/10.1016/j.dsx.2018.03.009

21. Kaplan RC, Tirschwell DL, Longstreth WT, Jr., Manolio TA, Heckbert SR, Lefkowitz D, et al. Vascular events, mortality, and preventive therapy following ischemic stroke in the elderly. Neurology. 2005;65:835-842. https://doi.org/10.1212/01.wnl.

\subsection{8.bb}

22. Burchfiel CM, Curb JD, Rodriguez BL, Abbott RD, Chiu D, Yano K. Glucose intolerance and 22-year stroke incidence. The Honolulu Heart Program. Stroke. 1994;25:951-957. https://doi.org/10.1161/ 01.str.25.5.951

23. Kissela BM, Khoury J, Kleindorfer D, Woo D, Schneider A, Alwell $\mathrm{K}$, et al. Epidemiology of ischemic stroke in patients with diabetes: the greater Cincinnati/Northern Kentucky Stroke Study. Diabetes Care. 2005;28:355-359. https://doi.org/10.2337/diacare.28.2.355

24. Kernan WN, Ovbiagele B, Black HR, Bravata DM, Chimowitz MI, Ezekowitz $\mathrm{MD}$, et al. Guidelines for the prevention of stroke in patients with stroke and transient ischemic attack: a guideline for healthcare professionals from the American Heart Association/ American Stroke Association. Stroke. 2014;45:2160-2236. https:// doi.org/10.1161/str.0000000000000024

25. Alva ML, Gray A, Mihaylova B, Leal J, Holman RR. The impact of diabetes-related complications on healthcare costs: new results from the UKPDS (UKPDS 84). Diabet Med. 2015;32:459-466. https://doi.org/10.1111/dme.12647

26. Acharya T, Huang J, Tringali S, Frei CR, Mortensen EM, Mansi IA. Statin use and the risk of kidney disease with long-term follow-up (8.4-year study). Am J Cardiol. 2016;117:647-655. https:// doi.org/10.1016/j.amjcard.2015.11.031

27. Collaboration PS. Age-specific relevance of usual blood pressure to vascular mortality: a meta-analysis of individual data for one million adults in 61 prospective studies. Lancet. 2002;360: 1903-1913. https://doi.org/10.1016/s0140-6736(02)11911-8

28. Rundek T, Sacco RL. Risk factor management to prevent first stroke. Neurol Clin. 2008;26:1007-1045, ix. https://doi.org/10. 1016/j.ncl.2008.09.001

29. Colhoun HM, Betteridge DJ, Durrington PN, Hitman GA, Neil HAW, Livingstone SJ, et al. Primary prevention of cardiovascular disease with atorvastatin in type 2 diabetes in the Collaborative Atorvastatin Diabetes Study (CARDS): multicentre randomised placebo-controlled trial. Lancet. 2004;364:685-696. https://doi. org/10.1016/S0140-6736(04)16895-5 